\title{
A monopodial rosette model of shoot formation as a program of secondary-aquatic grasses appearing
}

\author{
Natalya Savinykh ${ }^{*}$, and Svetlana Shabalkina \\ Vyatka State University, 610000 Kirov, Russia
}

\begin{abstract}
On the basis of comparative morphological analysis of the structure of life forms the concept "key biomorph" is offered; it is a mien of a plant which reflects adaptation to the conditions of a definite habitat (a static aspect, a model) and a definite stage in evolutional changes of biomorphs (a dynamical / evolutional aspect). The paper shows a comparative morphological range of key biomorphs in accordance with a monopodial rosette model of shoot formation per gradient of moisture increase in the direction: a floodplain meadow - shores, shore fronts - the water line - a water body. Polygonum bistorta is considered the original key biomorph, changes in it could occur in three lines: 1) Polygonum bistorta - Butomus umbellatus - Nuphar lutea; 2) Polygonum bistorta Scirpus lacustris - Eleocharis palustris; 3) Polygonum bistorta - Limosella aquatica - Stratiotes aloides. It seems that appearing of secondary-aquatic grasses with a monopodial rosette model of shoot formation was provided by the following modes of morphological evolution: deviation on the shoot level; abbreviation of the bud stage in shoot formation, in forming a part of the shoot (inflorescence), in the anatomic structure of the shoot and the ontogenesis of the original plant; prolongation of the bud phase in shoot development and ontogenesis of the genet.
\end{abstract}

\section{Introduction}

The look of the plant is mostly determined by the system of shoot formation. Shoot systems provide the most precise reaction of an organism to the peculiarities of the environment and to its adjustment to it. Taking into account the idea of I. G. Serebryakov that a life form demonstrates adaptation not only to the contemporary conditions of the environment, but also to the former ones [1], including the conditions of habitats with constantly changing degree of watering of the substrate, we offer the concept of "key biomorph" which is a mien of a plant which reflects adaptation to the conditions of a definite habitat (a static aspect, a model) and a definite stage in evolutional changes of biomorphs (a dynamical / evolutional aspect) [2]. It bears the name of a model plant species in Latin. Not to mix the concept with peculiarities of a definite species, the name of a key biomorph is not written in italics (for example, Polygonum bistorta).

*Corresponding author:savva_09@mail.ru 
Earlier [3] the role of a sympodial long-shoot model of shoot formation in forming shoot systems and in evolution of grasses of seasonal climate was shown. This paper considers possible changes in biomorphs with a monopodial rosette model which appear per gradient of moisture increase: a floodplain meadow - shores, shore fronts - the water line - a water body. The peculiar feature of this model consists in structural-functional differentiation of the shoot system into a vegetative axis of n-order and generative (or vegetative-generative) of $n+1$ order. The axis of $n$-order grows in a monopodial way, its functions are assimilating, storing, and potential renewal. The axes of $n+1$ order are annual, they provide seed propagation, they either grow from buds, or resemble vegetative shoots. The main module [4] of such plants is an oligo-cyclic oligo-carpic monopodial axis with vegetative and vegetative-generative zones, and a zone of secondary vegetative growing. Such an axis in its full is typical only of perennials. This axis in short-lived perennials and annuals of vegetative origin dies down early, so that it is not developed to the full.

The aim of the paper is to offer possible modes of evolutional changes of their mien per gradient of moisture increase in formation of secondary-aquatic grasses. It is to be done on the basis of analysis of data on shoot formation of plants with a monopodial rosette model.

\section{Material and Methods}

It is known that change of biomorphs at secondary colonization of water bodies per gradient of moisture increase has taken place in the direction from floodplain meadows through shore fronts and water line to a water body. So to achieve the aim of the research the peculiar features of the structure of shoot systems and life forms of the model species of the habitats Polygonum bistorta L., Butomus umbellatus L., Eleocharis palustris (L.) Roem. Et Schult., Limosella aquatica L. are characterized. Shoot formation and the mien of the species correspond to the key biomorphs. The material for the analysis was collected during field research on the model areas, mostly in the vicinity of Kirov in 2013-2020. The scheme of biomorph transformation was drawn with the use of comparatively morphological [5] and biomorphological methods [6], regulations on model organization [7], poly-variability of development [8], time and type of morphological disintegration [9], modes of morphological evolution [10].

\section{Results and Discussion}

Apparently, the original and the most analogous to the mien of mesophytes with a monopodal rosette model in conditions of periodical watering is the biomorph Polygonum bistorta. It is a policarpic, a perennial, a vegetatively slightly mobile non-saliently polycentric grass with a non-specialized normal partial morphological disintegration. The axes of n-order are perennial vegetative rosette ones with leaves of medial formation; side axes are annual prolonged vegetative-generative polymetameric ones with assimilating leaves gradually decreasing in size to the peak, formed from hibernating buds [11]. As for their rhythm of development and structure, vegetative-generative shoots resemble monocarpic shoots of renewal of perennial grasses, but, as for their place in the shoot system (lateral axes) and absence of structural-functional zonal distribution, they differ from them. The main mode coincides with the universal mode, it is an oligo-cyclic oligocarpic monopodially growing axis. According to the classification of C. Raunkiaer [12], these plants are hemicryptophytes. The miens of the mesophytes of species of the geni Alchemilla L. and Sanguisorba officinalis L., as well as Geum rivale L., from the places of changeable moistening / watering are analogous to the biomorph Polygonum bistorta. 
The water line is a habitat of the gelophyte Butomus umbellatus. Structurally its main biomorph resembles Polygonum bistorta. Still the genitive shoots are developed from vegetative buds (they are placed in angles of leaves of medial formation of the current annual gain), without leaves; the vegetative-generative part of the axis resembles an intercalary frondose inflorescence of mesophyte grasses. Morphological disintegration is early, so these plants are short-lived perennials of vegetative origin. Rooting of the axis after growth provides an evident unity of a compact clone [13]. This plant is a helophyte with renewal buds in the substrate, its key biomorph is Butomus umbellatus.

Scirpus lacustris grows both close to the water line and in some depth. It differs from Butomus umbellatus by the fact that its vegetative axis leaves are reduced to chaff. The vegetative-generative shoot is a semi-rosette one, evidently, it is formed, analogoues to Polygonum bistorta, from the buds of the previous increment. Its vegetative part has two short internodes, nodes with the first leaf reduced to chaff and the second leaf underdeveloped. There is a bud in the sinus of a squamose leaf, it is able to give start to new axes of the plant and to provide branching. Up from the rosette part there is a green spear with a terminal inflorescence, it fulfills propagative and assimilating functions [13]. Thus, Scirpus lacustris, alongside with its peculiar features, has some similar features both with Polygonum bistorta, and with Butomus umbellatus. The shoot systems of these biomorphs include sleeping buds. Apparently it is the result of competition in the shoot system of a plant due to lack of living space in conditions of an inapparently polycentric type of biomorph and it forms a store of buds for future propagation of specimens and secondary colonization of the space already taken.

According to this model the aquatic plant Nuphar lutea develops shoot systems. Like Butomus umbellatus, they have leaves of medial formation, a green axis of the lateral shoot, special intercalary inflorescences, scarce lateral shoots with interspersed branching, and a sparing vegetative axis which is thickened due to modular thickening of the stem [13]. Development of the axis of Nuphar lutea was described in detail [14]; it is proved that it has a lateral axis, like Scirpus lacustris, two metamers with short internodes and reduced leaves, and formation of elements of an only flower on its peak.

Descending of short-root hydrophytes Nuphar lutea from mesophyte original forms was possible through the model Butomus umbellatus. In the line: Polygonum bistorta Butomus umbellatus - Nuphar lutea - the model of shoot formation is fully preserved (Fig.); the time of morphological disintegration changes: it takes place earlier (acceleration in the vegetative sphere of the plant). The plant becomes a short-lived perennial of vegetative origin. Florescence is provided by development of lateral axes without a dormant period, the inflorescence is reduced to one flower in course of terminal abbreviation of the lateral axis. Plants keep their territory due to rooting and fixation of ramets, the territory is occupied repeatedly by means of gradual realization of dormant buds.

The mien of Scirpus lacustris with reduction of leaves of medial formation and green assimilating axes of the inflorescence apparently demonstrates one more way of providing the necessary area of photosynthesizing surface and overcoming the consequences of specimens' competition at colonizing water bodies. Due to reduction of leaves of a vegetative axis the plant is able to form a tangle near the shores and to get into the depth of a water body; lateral axes provide both air respiration and seed reproduction. Evident links with Polygonum bistorta and Nuphar lutea allow considering Scirpus lacustris an individual line in transforming life forms at colonizing water bodies by flowering plants (Fig.).

A special place among plants in conditions of periodical moistening / watering is occupied by Eleocharis palustris. It grows on yearly flooded areas of the shore down the depth of 50-80 sm, it is a helophyte. It is a polycarpic, a short-lived perennial of vegetative origin with an early full specialized morphological disintegration, it has a monopodially growing axis of n-order (with long internodes) and a lateral partial formations of rosette 
shoots. Rosette shoots are formed in course of iterative branching of specialized semirosette lateral shoots, like those of Scirpus lacustris (but without green cataphyll). From the axillary bud of this shoot a new monopodial rosette axis is formed with similar specialized lateral green axes of inflorescences. The model of shoot formation of these structures is a typical monopodial rosette one. In conditions of intense shading (in case of burying the shoots in a layer of silt or in case of strong competition between separate elements of the specimen) at the top of such an axis the internodes prolong, and the shoot formation model becomes a monopodial semi-rosette one, and in case of die-away of basalis rosette parts the shoot formation model is similar to a long-shoot one [15]. Formation of long internodes of these specimens is considered a recapitulation (a specific reaction at shading); it provides spreading of the plant.

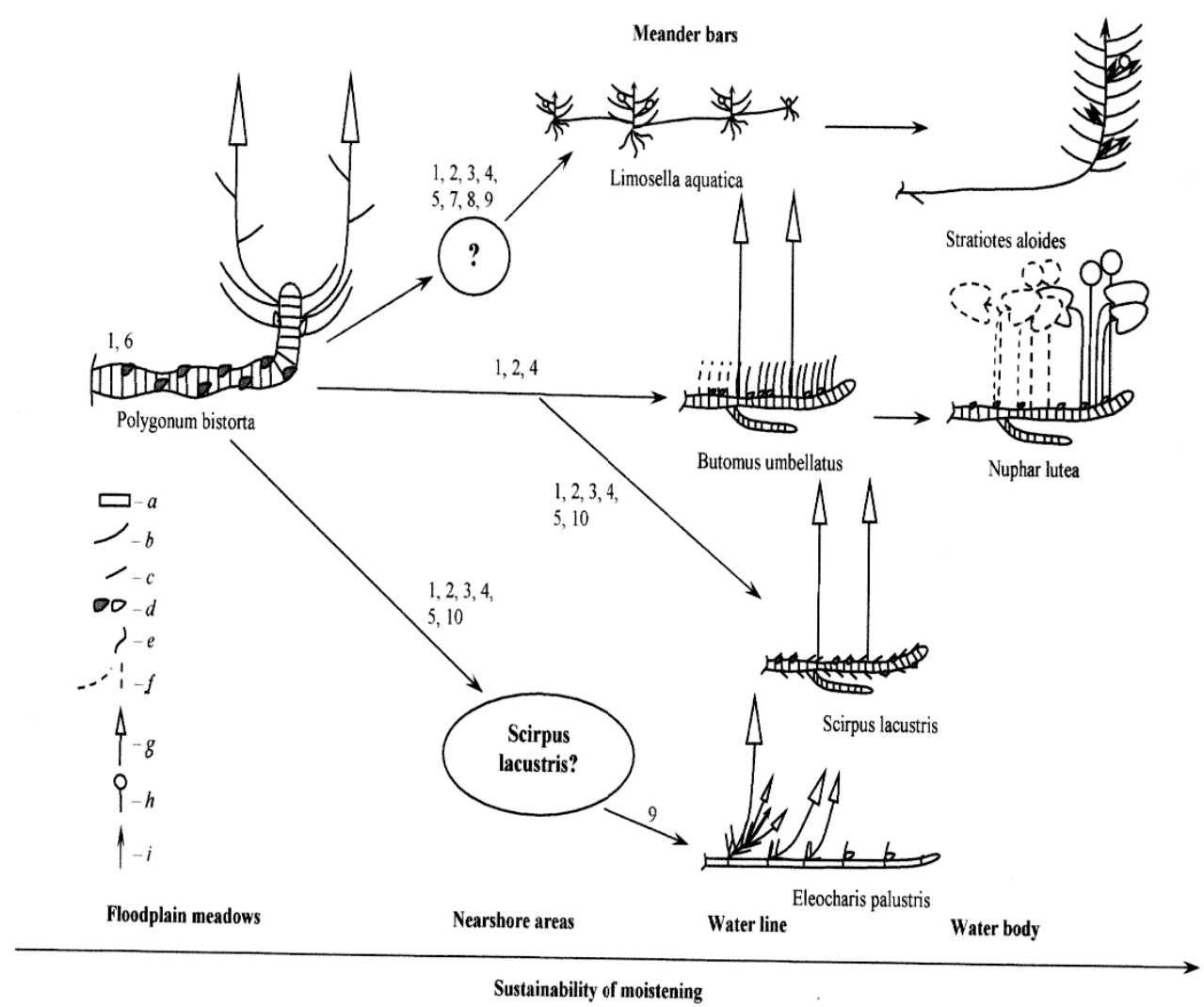

Fig. Model of the plant biomorph transformation: $a$ - metamere; $b$ - middle formation leaf; $c$ - scaly leaf; $d$ - bud; $e$ - site of morphological disintegration; $f$ - died-off parts of shoots; $g$ - inflorescence; $h$ - flower; $i$ - vegetative shoot; numbers in the scheme (1-10) - processes resulting in biomorph transformation (explanations in the text)

The biomorph Eleocharis palustris shows a special life strategy of plants on porous substrates near the water line. Its connection with Scirpus lacustris is evident. The long line "Polygonum bistorta - Scirpus lacustris - Eleocharis palustris" is specific for reduction of assimilating surface of the original axis, early morphological disintegration, iterative branching at forming lateral shoot systems as centres of establishment and formation of polycentric specimens (Fig.).

Meander bars take a special place among habitats with variable watering. Limosella aquatica is one of numerous monocarpic therophytes. It is a vegetatively mobile frankly 
polycentric grass with a rosette shoot of n-order and upper-rosette rooting shoots of $n+1$ order (up to 14 in one specimen) and the following (up to 4) branching orders. During a vegetation period each metamer of the original specimen develops axillary complexes from the dormant main and successive buds with many fruit. Along the axis of the shoot these complexes change in the following succession: a fruit, a stolon-rosette shoot or a system of them; a flower and a bud; a flower bud and a bud [16]. The mentioned structures, homologues as for their place on the axis, demonstrate a possible transformation of lateral specialized shoots into one flower. Vegetative support of the coenopopulation, which is quite possible in case the long internode died away, under the circumstances, was not used in the process of natural selection, apparently, for the reason that the stream flows at a high speed and the plants get buried during the flood. Like typical annuals-therophytes, Limosella aquatica is a monomodule plant, it is developed by one main module - a system of a mature monopodial shoot with several branching orders; but, unlike most monocarpics, it is a polycentric plant. The similar feature with the model Polygonum bistorta consists in the rosette character at the starting stages of ontogenesis. The difference consists in shortening the bud phase of development of lateral shoots, in iterative branching, in absence of storing function of the original axis, and in reduction of the side vegetative-generative shoot to one flower. Acceleration is evident in both vegetative and productive spheres; during a comparatively short vegetative season alternative and prolonged in time fruit and seeds formation takes place; it contributes to the possibility of successful seed reproduction of the monocarpic-therophyte in conditions of late drying of meander bars. Excellently adaptive to the conditions of sand beaches as it is, the biomorph Limosella aquatica could be the initial, parent one for farming stolon-rosette hydrophytes of the type of Stratiotes aloides.

\section{Conclusion}

The data acquired prove the modes of morphological evolution which were stated earlier, they provide colonization of water bodies with flowering plants with other models of shoot formation, such as deviation, prolongation, and abbreviation on the level of specimens and separate shoots as their specific features; the end body of the transformations are short-lived perennials and annuals of vegetative origin, and therophytes. Secondary colonization of water bodies with plants with a monopodial rosette system of shoot formation was provided with the following processes and modes of morphological evolution (Fig.):

1 - differentiation of the shoot system according to their functions: an axis - vegetative, lateral shoots - reproductive (deviation on the level of a shoot);

2 - early morphological disintegration (abbreviation of ontogenesis of the initial specimen and prolongation of ontogenesis of the genet);

3 - iterative branching (abbreviation of the bud phase in development of a shoot);

4 - acceleration in the vegetative sphere (abbreviation of ontogenesis of the initial specimen and prolongation of ontogenesis of the genet);

5 - acceleration in the reproductive sphere (abbreviation of ontogenesis of a specimen);

6 - presence and realization of dormant buds (prolongation of the bud phase in development of a shoot);

7 - reduction of the lateral vegetative-generative shoot to one flower (abbreviation in forming a part of a shoot - an inflorescence);

8 - reduction of the storing function of a shoot of n-order (abbreviation of a shoot);

9 - prolongation of internodes - prolongation on the shoot level;

10 - reduction of the assimilating function of a shoot of n-order (basal abbreviation in development of a leaf). 
These peculiarities of adaptation in development of shoots and plants indicate the possibilities of changes miens of plants in case of their secondary colonization of water bodies, different combinations are possible for their realization.

The research was carried out with partial financial support of the Russian Foundation for Basic Research (projects № 13-04-01-057, № 16-04-01073)

\section{References}

1. L. M. Shafranova, L. E. Gatsuk, N. I. Shorina, Biomorphology of the Plants and Its Influence on Development of Ecology (Moscow, 2009)

2. N. P. Savinykh, S. V. Shabalkina, «Key» biomorphs as stages in the evolution of secondary aquatic grasses, in Proceedings of IX International scientific conference on aquatic macrophytes «Hydrobotany 2020», 17-21 October, Borok (2020)

3. N. P. Savinykh, S. V. Shabalkina, Contemp. Probl. Ecol. 13, 3 (2020)

4. N. P. Savinykh, Genus Veronica L.: Morphology and Evolution of Life Forms (Kirov, 2006)

5. I. G. Serebryakov, Field Geobotany 3 (1964)

6. A. P. Khokhryakov, Evolution of the Plant Biomorphs (Moscow, 1981)

7. N. P. Savinykh, Paleontol. J. 49, 14 (2015)

8. L. A. Zhukova, Population Life of Meadow Plants (Yoshkar-Ola, 1995)

9. Plant Cenopopulations: General Terms and Structure (Moscow, 1976)

10. T. I. Serebryakova, Zh. Obshch. Biol. 44, 5 (1983)

11. N. P. Savinykh, M. I. Kovalkova, A. V. Mazeeva, K. R. Shamsuvalieva, Peculiarities of the shoot formation Bistorta officinalis Delarbre as an adaptation to the conditions of variable moisture, in Proceedings of XIII All-Russian scientific and practical conference with international participation, 1-2 December, Kirov (2015)

12. C. Raunkiaer, The life forms of plants and statistical plant geography (Oxford, 1934)

13. N. P. Savinykh, S. V. Shabalkina, E. V. Lelekova, Contemp. Probl. Ecol. 8, 5 (2015)

14. E. S. El, M. V. Remizowa, D. D. Sokoloff, Front Cell Dev Biol. 8, 303 (2020)

15. N. P. Savinykh, E. A. Mikhaylova, Shoot formation and biomorph Eleocharis palustris (L.) R. Br., in Proceedings of XIV All-Russian scientific and practical conference with international participation, 5-8 December, Kirov (2016)

16. N. Savinykh, M. Shakleina, BIO Web Conf. 16 (2020) 